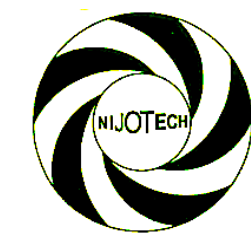

Nigerian Journal of Technology (NIJOTECH)

Vol. 39, No. 2, April 2020, pp. 506 - $\mathbf{5 1 3}$

Copyright@ Faculty of Engineering, University of Nigeria, Nsukka

Print ISSN: 0331-8443, Electronic ISSN: 2467-8821

www.nijotech.com

http://dx.doi.org/10.4314/njt.v39i2.21

\title{
WEARABLE INFRA-RED PRE-SCREENING SMARTBRA FOR EARLY DETECTION OF BREAST CANCER
}

\author{
E. O. Nwoye ${ }^{1}$, O. P. Fidelis ${ }^{2}, *$ and O. Ogunsolu ${ }^{3}$ \\ 1, 3, Department of BiomedicAl Engineering, UniVersity of LAGOS, AKOKA YABA, LAGOS STATE, NIGERIA \\ 2, DePt of Biomedical TeChNology, Federal University of TeChNology, AKURE, ONDO State, NIGERIA
}

E-mail addresses: 1 enwoye@unilag.edu.ng, ${ }^{2}$ opfidelis@futa.edu.ng, ${ }^{3}$ kemioogunsolu1@gmail.com

\begin{abstract}
Breast cancer is the most common cancer in women worldwide, comprising $16 \%$ of all female cancers and early diagnosis remains an important detection strategy. The aim of this study was to design and implement a user-friendly SmartBra. An infra-red (IR) imaging sensor was deployed to determine the temperature profile of the breast for this application. The device was tested with approval from the Health Research Ethics Committee of the Lagos University Teaching Hospital using healthy persons and persons already diagnosed with different stages of breast cancer. The results showed high sensitivity and specificity with good intra-examiner reliability for absolute values of mean temperature for the right breast and very good reproducibility for the left breast. Data for healthy participants revealed that the difference in absolute temperature between the left and right breast was less than $1^{\circ} \mathrm{C}$, while that of the sick (cancer) participants indicated values greater than $1^{\circ} \mathrm{C}$. The device is safe and easy to use and therefore can serve as an adjunct diagnostic device for early detection of breast cancer.
\end{abstract}

Keywords: breast cancer, early detection, infra-red thermography, mammography.

\section{INTRODUCTION}

Breast cancer is a major disease condition both in terms of incidence rate and mortality among women [1], comprising $16 \%$ of all female cancers [2] and is the leading cause of cancer deaths in Africa [3] with case fatality rates highest in low- and middle-income countries [4,5]. Although manifestation of cancer is not exclusive to women, the incidence is one hundred times higher in women compared to men [6]. This may be attributed to late diagnosis, in which case the cancer has manifested or metastasized. On the other hand, when diagnosis is early, the survival index improves $[7,8]$ and can go up to $95 \%$ [9]. A number of techniques aimed at early detection of breast cancer have been implemented over the years. Among these, mammography is the most popular and most used tool to detect breast cancer [10]. However, it presents certain disadvantages vis-a-viz its accompanying pain and the unavoidable exposure to ionizing radiation [11]. There is also the challenge of detecting small-sized tumours in women with dense breast tissue [12]; and in some countries, mammography is only applied to women over 40 years old once or twice a year. As a result of these, the use of additional non-invasive, non-ionizing sensing technologies to facilitate early detection and diagnosis of breast cancer (whilst ameliorating the problems presented in mammography) is important to increase the chances of survival [13].

Early writings of Hippocrates around 480 B.C. have been reported to first present recorded use of thermo-biological diagnostics. Mud slurry was often spread over a patient and allowed to dry whilst noting the rate of drying on different parts of the body and the body areas that dried first were thought to be indicative of underlying organ pathology [14]. Technological advancements have since led to the use of multiple sensors in daily life and in very specific fields. In literature, the use of

* Corresponding author, tel: +234-803-819-3799 
sensors for cancer detection and treatment is well documented. For example, hyperspectral cameras have been used for the detection of gastric cancer [15]. Sensors have been deployed to minimize needle deflection in cancer treatment [16] and to minimize pain which may be associated with treatments [17].

Temperature is an important physical feature and its measurement is commonly used as a diagnostic tool in industrial and medical fields [13]. There are multiple techniques used for heat measurement, one of which is Infrared Thermography [18]. Infrared (IR) sensing is a technology which importance has grown in the last few years in multiple applications. IR thermography is a non-destructive technique that measures the infrared radiation emitted by a body whose temperature is above absolute zero [10].

IR thermography is used to analyze the delamination in composites $[19,20]$ and to perform the automatic detection of defects in materials [21]. In medical applications, IR thermography is widely accepted largely because it is safe (non-ionizing), noninvasive and cost-effective [22]. Some of its applications include the treatment of diabetes [23], quick detection of seasonal influenza [24], study of eye diseases [25], analysis of chronic pain [26] and mainly in the diagnosis of cancer [27]. Cancer diagnosis using IR thermography is possible because the presence of tumours have been reported to cause an increment of temperature on the skin surface [28]. Temperature difference between cancerous tissues and unaffected tissues is reported to result from elevated levels of tumour metabolism, vascularity and perfusion within the cancerous tissues [29, 30]. As a result, the use of Infrared sensing technology in the detection of multiple types of cancer, such as melanoma [31], is possible.

Studies have shown that the IR thermography technique has the ability to detect tumours that are $3 \mathrm{~cm}$ in size and are located deeper than $7 \mathrm{~cm}$ from the skin surface and tumours smaller than $0.5 \mathrm{~cm}$ can be detected if they are close to the surface of the skin [32, 33]. One study [34], observed that when a mammogram was conducted on patients with suspicious clinical examinations, the sensitivity was found to be $83 \%$. A combination of mammogram and thermogram increased the sensitivity to $93 \%$. When all three methods (clinical examination, mammogram and thermogram) were considered, the sensitivity was found to be $98 \%$. Another study [35] conducted a multi-center 4-year clinical trial at five institutions using infrared imaging of patients for whom breast biopsy had been recommended. The authors reported that in the 875 biopsied lesions, the index of suspicion resulted in $97 \%$ sensitivity, $14 \%$ specificity, $95 \%$ negative predictive value and $24 \%$ positive predictive value. Therefore, the aim of the study is to harness the non-invasive, non-ionising and cost effective advantages of infrared thermography for the development of a SmartBra as an adjunct to mammography and ultrasound and to facilitate early detection of breast cancer in women.

\section{MATERIALS AND METHOD}

\subsection{Materials}

The materials used in the development of the SmartBra include IRT Sensor: Adafruit AMG8833 Grid-EYE Breakout (Adafruit NYC. USA), Microcontroller: TEENSY 3.2 (Shenzhen Chipskey Tech. Co., Ltd, China), LCD Image display: TFT display (WINSTAR Display Co., Ltd. Taiwan), Power batteries and Leather fabric.

\subsection{Design}

Thermal imaging sensor operates on the principle that emissivity of human skin is high and infrared radiation emitted by the skin can be converted directly into temperature. Thus, infrared imaging is a method of evaluating surface temperature of a body [36]. To detect pathology within the human breast (such as cancer), the temperature difference of an area of the breast is measured. Sensor (AMG8833) is capable of detecting tiny differences in temperature within the breast. It collects infrared radiation from objects in an area and creates an electronic image based on temperature differences because objects are rarely of precisely the same temperature as object(s) in their neighbourhood. The SmartBra with temperature monitoring function, comprise of a left and right bra cup (in which the infrared sensor is embedded), a battery assembly, intelligent image acquisition system and the display as shown in Figure 1.

The system architecture is shown in Figure 2 and the device is powered using direct current (from a rechargeable battery source).

The device can detect differences in temperature within the breast and these differences appear as distinct colours on the thermograph as shown in the results. 


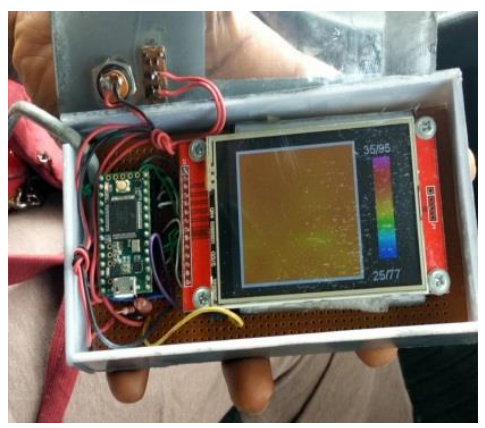

$\mathrm{A}$

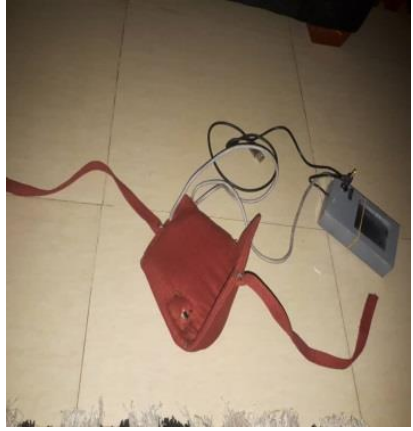

B

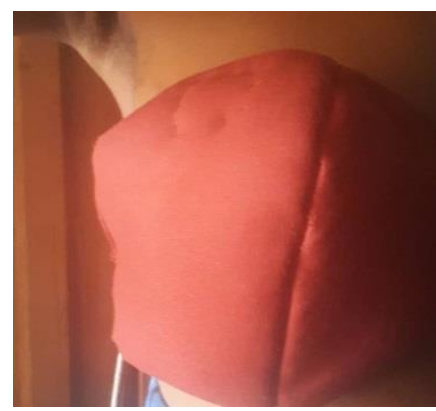

$\mathrm{C}$

Figure 1: (A) The Image processing and display unit, (B) The wearable leather attachment connected to the imaging system and $(C)$ a picture showing how the SmartBra fits on a user.

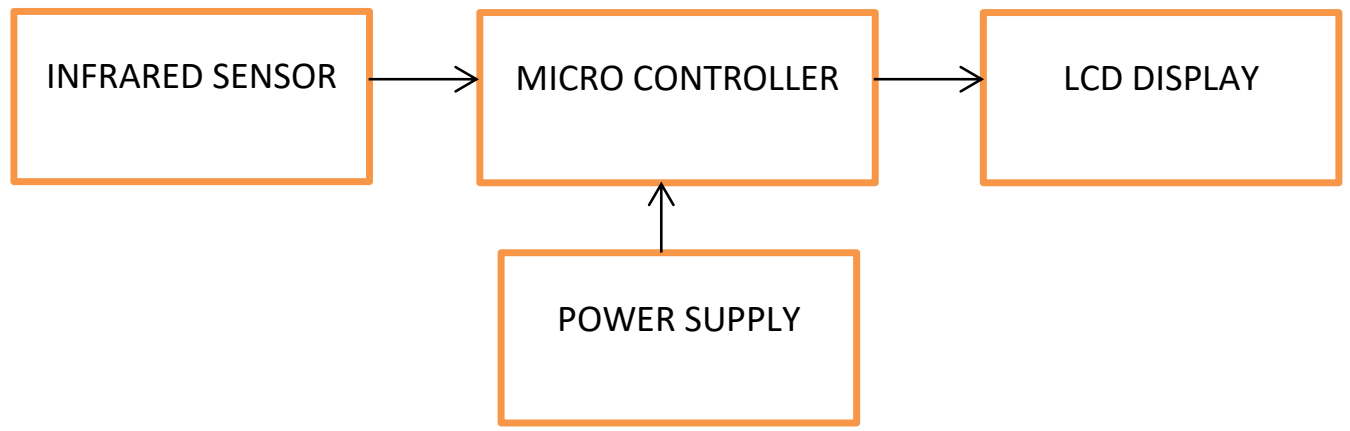

Figure 2: System architecture for the infra-red smartbra design

\subsection{Study Participants}

Participants were recruited in accordance with the health research guidelines of Lagos University Teaching Hospital (LUTH), Lagos, Nigeria, and an informed consent was obtained from each participant. Participants were volunteers consisting of ten (10) patients admitted to LUTH and were divided into control and tumour groups ( $n=5$ per group). The inclusion criteria for the control group were absence of mammary nodules, normal physical and skin examination. The tumour group was made up of female volunteers with diagnosed mammary tumor, regardless of the number and size of nodules. The participants were asked to avoid the use of lotions, perfumes, deodorants and cosmetic creams; to not shave the breast area on the test day; to avoid the intake of alcohol and caffeinated drinks at least 24-hours before test; avoid smoking 2-hours before test and to avoid exercise 1 hour before test [13]. The examinations were carried out with the support of a group of nurses. In this way, the requirements of standard medical procedures were ensured.

The reproducibility of the thermal pattern is important if medical infrared thermography is to be used as a screening tool. Thus, a three (3) days pre-study was conducted to evaluate the day-to- day repeatability of the device [37]. This was necessary as reliable measurements have a substantial impact on the diagnosis and interpretation of pathophysiological abnormalities [31]. In addition, to ensure validity of the test results, the participants were allowed to relax for up to 25 minutes inside the test room [13] to attain the recommended optimal thermal stability prior to diagnosis.

\section{RESULTS AND DISCUSSION}

The results obtained from the evaluation of the device using healthy, undiagnosed $(\mathrm{H} 1-\mathrm{H} 5)$ participants are shown in Figures 3-7. The temperature distribution across each breast is indicated by different colour patches on the breast images as shown. The temperature distribution of the breasts of each study participant (healthy and without breast cancer) was analysed and is presented in Tables 1 and 2 .

The temperature distribution of the breasts of each study participant (already diagnosed with breast cancer) was analysed and is presented in Tables 3 and 4.

The images from participants already diagnosed as having cancer (using other techniques) were also 
obtained using the smartbra device as shown in Figures $8-12$.

The result in Table 3 (sick cases) shows the average temperature difference is $1.82^{\circ} \mathrm{C}$, which is markedly higher than the result presented in Table 1 for healthy cases participants $\left(0.32^{\circ} \mathrm{C}\right)$. The maximum value and mean \pm standard deviation presented are also higher than in the healthy cases. The difference in the average temperature

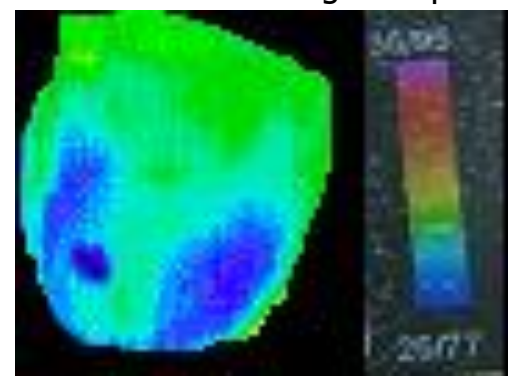

(a) and that of the individual participants are all greater than $1^{\circ} \mathrm{C}$, an indication of the possibility of inflammation of the breast.

The highest temperature difference is $2.23^{\circ} \mathrm{C}$ and the least was $1.32{ }^{\circ} \mathrm{C}$, both greater than $1^{\circ} \mathrm{C}$.

Previous studies have demonstrated that thermal images from the two sides of the body are usually symmetrical $[38,39]$.

Figure 3: (a) right and (b) left breast of a healthy (undiagnosed) participant, $H 1$.

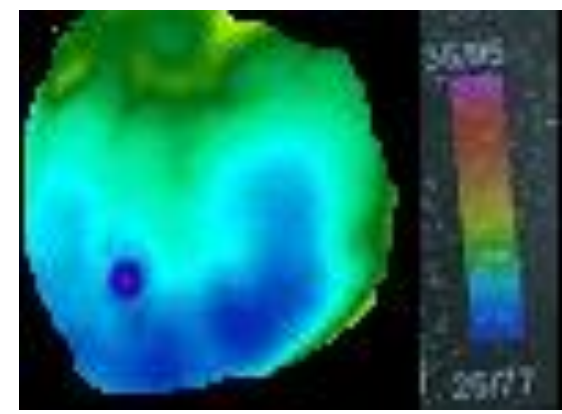

(a)

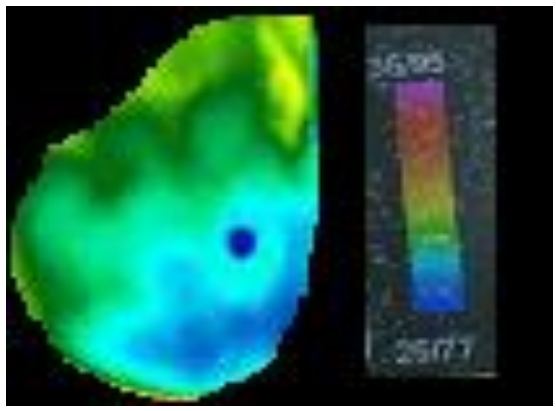

(b)

Figure 4: (a) right and (b) left breast of a second healthy (undiagnosed) participant, H2

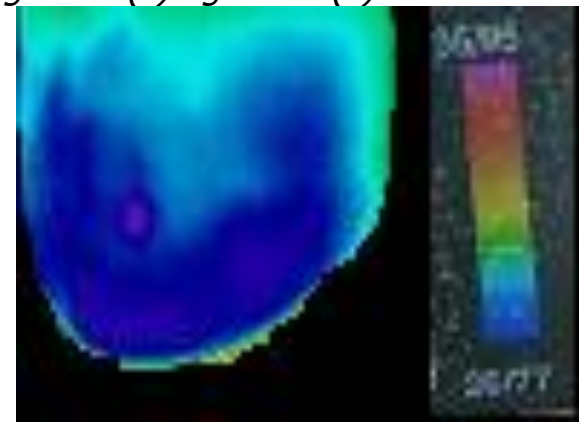

(a)

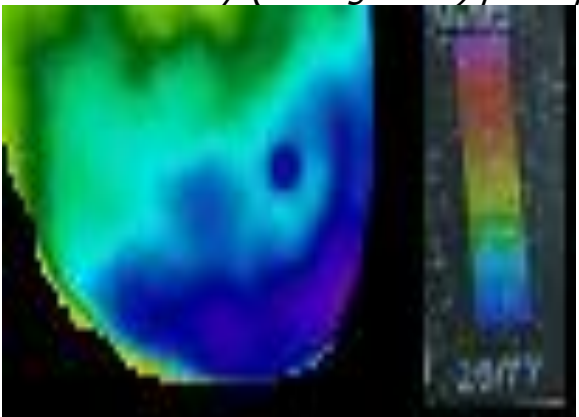

(b)

Figure 5: (a) right and (b) left breast of a third healthy (undiagnosed) participant, $\mathrm{H3}$

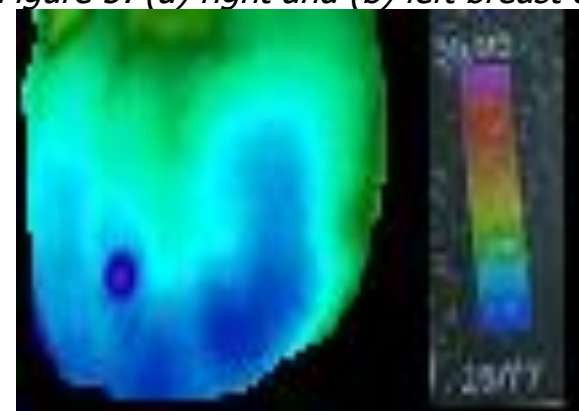

(a)

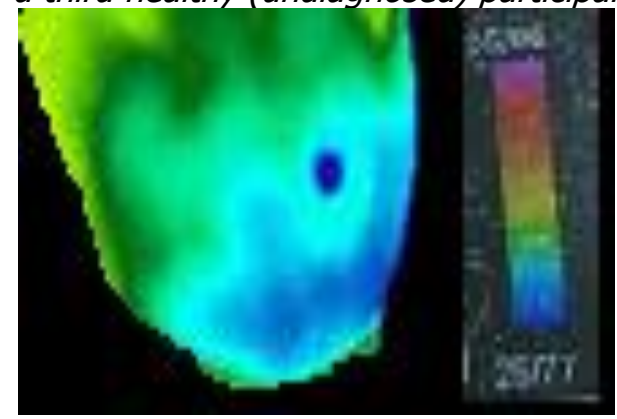

(b)

Figure 6: (a) right and (b) left breast of a fourth healthy (undiagnosed) participant, $\mathrm{H} 4$ 


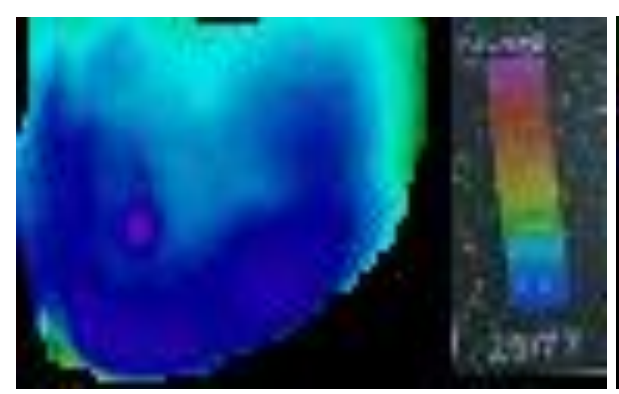

(a)

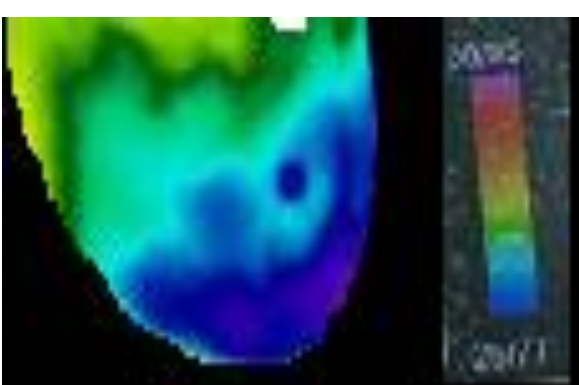

(b)

Figure 7: (a) right and (b) left breast of a fifth healthy (undiagnosed) participant, H5

Table 1: Temperature differences between breasts in study participants who are not diagnosed with breast

\begin{tabular}{llll}
\hline \multicolumn{4}{c}{ cancer } \\
\hline Participant & $\begin{array}{l}\text { Temperature of right } \\
\text { breast }\left({ }^{\circ} \mathrm{C}\right)\end{array}$ & $\begin{array}{l}\text { Temperature of left } \\
\text { breast }\left({ }^{\circ} \mathrm{C}\right)\end{array}$ & $\begin{array}{l}\text { Temperature } \\
\text { difference }\left({ }^{\circ} \mathrm{C}\right)\end{array}$ \\
\hline $\mathrm{H} 1$ & 33.78 & 33.31 & 0.47 \\
$\mathrm{H} 2$ & 33.74 & 33.93 & 0.19 \\
$\mathrm{H} 3$ & 33.17 & 33.49 & 0.32 \\
$\mathrm{H} 4$ & 33.67 & 33.91 & 0.24 \\
$\mathrm{H} 5$ & 33.09 & 33.45 & 0.36 \\
\hline
\end{tabular}

Table 2: Temperature averages for all five healthy participants

\begin{tabular}{llll}
\hline Temperature & Right breast $\left({ }^{\circ} \mathrm{C}\right)$ & Left breast $\left({ }^{\circ} \mathrm{C}\right)$ & $\begin{array}{l}\text { Temperature } \\
\text { difference }\left({ }^{\circ} \mathrm{C}\right)\end{array}$ \\
\hline Mean \pm SD & $33.49 \pm 0.69$ & $33.62 \pm 0.62$ & $0.13 \pm 0.07$ \\
Maximum & 33.78 & 33.93 & 0.15 \\
Minimum & 33.09 & 33.31 & 0.22 \\
\hline
\end{tabular}

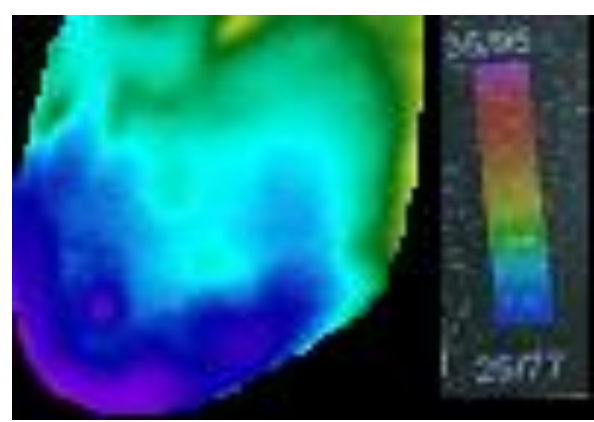

(a)

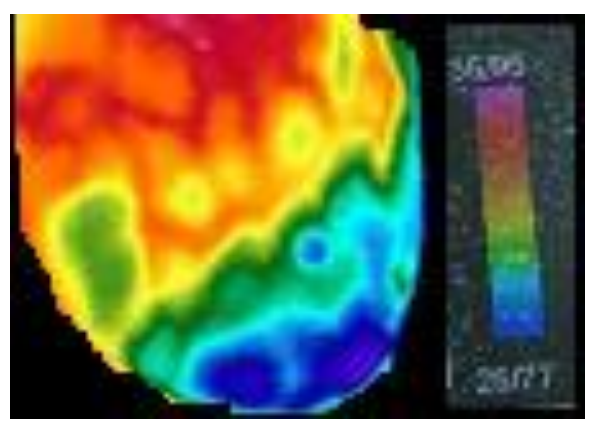

(b)

Figure 8: (a) right and (b) left breast of a participant already diagnosed with breast cancer, S1

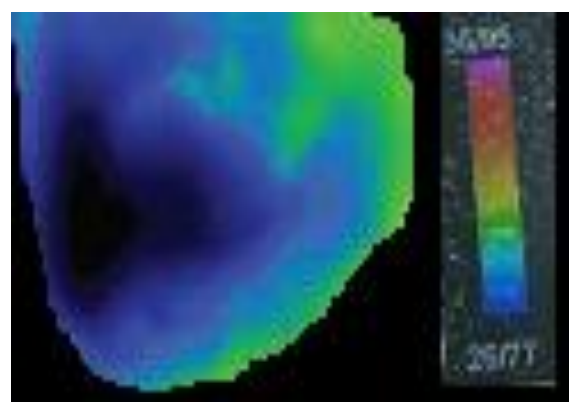

(a)

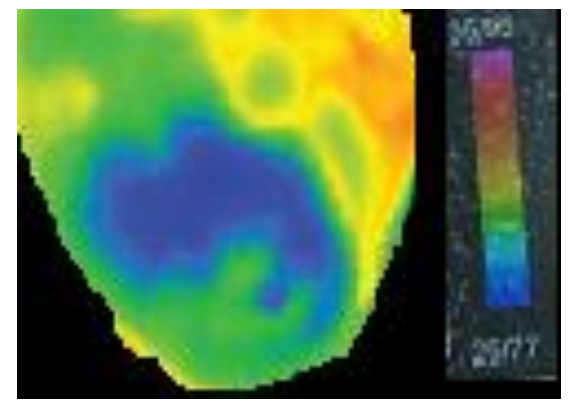

(b)

Figure 9: (a) right and (b) left breast of a second participant already diagnosed with breast cancer, S2 


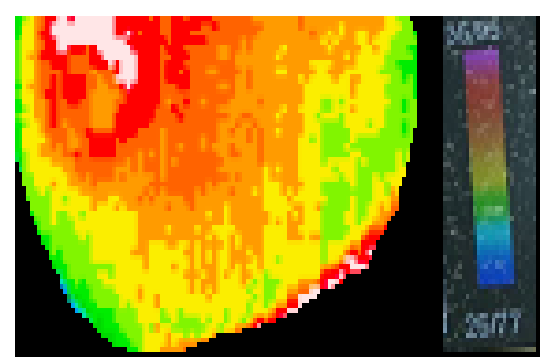

(a)

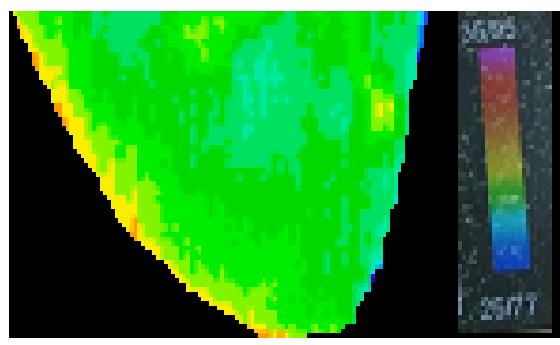

(b)

Figure 10: (a) right and (b) left breast of a third participant already diagnosed with breast cancer, S3

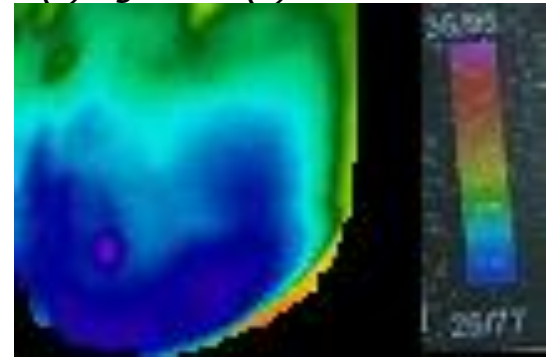

(a)

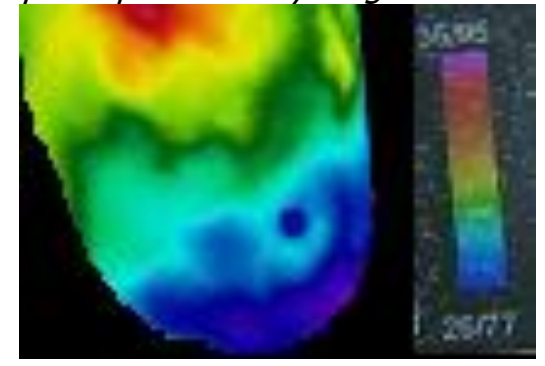

(b)

Figure 11: (a) right and (b) left breast of a fourth participant already diagnosed with breast cancer, S4

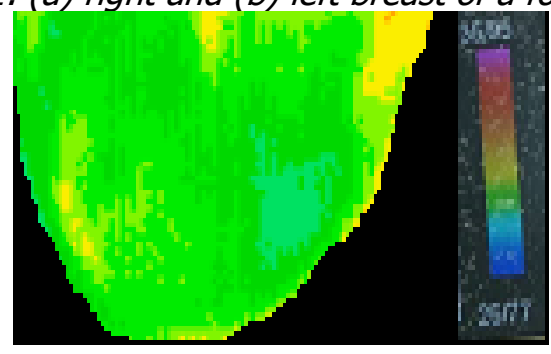

(a)

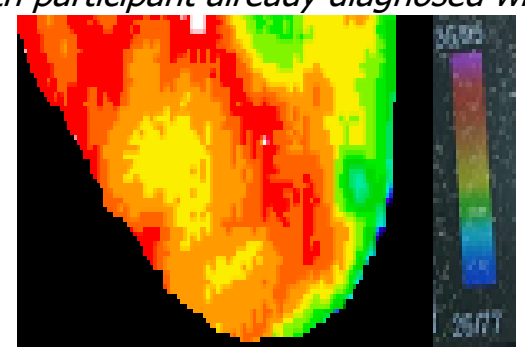

(b)

Figure 12: (a) right and (b) left breast of a fifth participant already diagnosed with breast cancer, S5

Table 3: Temperature difference between breasts in study participants who have been diagnosed with breast cancer.

\begin{tabular}{llll}
\hline Participant & $\begin{array}{l}\text { Temperature of right } \\
\text { breast }\left({ }^{\circ} \mathrm{C}\right)\end{array}$ & $\begin{array}{l}\text { Temperature of } \\
\text { breast }\left({ }^{\circ} \mathrm{C}\right)\end{array}$ & left \\
\hline S1 & 33.11 & 35.34 & 2.23 \\
S2 & 33.86 & 35.72 & 1.86 \\
S3 & 36.03 & 34.71 & 1.32 \\
S4 & 33.07 & 35.02 & 1.95 \\
S5 & 34.62 & 36.35 & 1.73 \\
\hline
\end{tabular}

Table 4: Temperature averages for all five participants already diagnosed with cancer

\begin{tabular}{llll}
\hline Temperature & Right breast $\left({ }^{\circ} \mathrm{C}\right)$ & Left breast $\left({ }^{\circ} \mathrm{C}\right)$ & Difference $\left({ }^{\circ} \mathrm{C}\right)$ \\
\hline Mean \pm SD & $34.12 \pm 5.2$ & $35.43 \pm 1.64$ & $1.31 \pm 3.56$ \\
Maximum & 36.03 & 36.35 & 0.32 \\
Minimum & 33.07 & 34.71 & 1.64 \\
\hline
\end{tabular}

Significant asymmetry (ranging from $1^{\circ} \mathrm{C}$ to $2.5^{\circ} \mathrm{C}$ ) can be considered suspicious [40] and may indicate a physiologic or anatomical variant in the breast; while temperature difference of $1^{\circ} \mathrm{C}$ can be used to detect problems such as cancer and angiogenesis [41]. These differences can be used also to detect the presence of benign tumours. By comparing one side of the breast with the other, it may be possible to detect subclinical problems before they are clinically relevant [13]. The results from this study indicate that the SmartBra is effective as an adjunct diagnostic tool in the early detection of breast cancer; with the potential of reducing the rate of breast cancer mortality due to late diagnosis.

\section{CONCLUSION}

The aim of the study which is to develop a diagnostic device for breast cancer based on infrared thermography was realised. It is hoped that the device will improve the culture of regular breast examination 
among women. The device is intended to be costeffective and user-friendly. It is designed to serve as a do-it-yourself examination kit and can be used more often than mammography given that it is non-ionising and therefore relatively safer.

\section{ETHICAL CONSIDERATIONS}

The study was approved by the Health Research Committee of Lagos University Teaching Hospital (LUTH), Lagos, Nigeria, with approval number ADM/DCST/HREC/2125.

\section{CONFLICT OF INTEREST}

The Authors declare that they have NO competing interest with reference to this study.

\section{REFERENCES}

[1] Peng, L. Chen, W. Zhou, W. Li, F. Yang, J. Zhang, J. "An immune-inspired semi-supervised algorithm for breast cancer diagnosis", Comput. Methods Programs Biomed. 2016, Vol. 134, pp. 259-265.

[2] Fitzmaurice, C. Dicker, D. Pain, A. et al., (2015). "The global burden of cancer 2013", JAMA Oncology, Vol. 1, pp. 505-527.

[3] Farmer, P. Frenk, J. Knaul, F.M. "Expansion of cancer care and control in countries of low and middle income: a call to action", The Lancet, 2010, Vol. 376, No. 9747, pp. 1186-1193.

[4] Mody, G.N. Nduaguba, A. Ntirenganya, F. and Riviello, R. "Characteristics and presentation of patients with breast cancer in Rwanda," The American Journal of Surgery, 2013, Vol. 205, No. 4, pp. 409-413.

[5] Ferlay, J.S.I. Ervik, M. Dikshit, R. Eser, S. Mathers, C. Rebelo, M. Parkin, D.M. Forman, D. and Bray, F. "Cancer Incidence and Mortality Worldwide" In: Proceedings of the International Agency for Research on Cancer, Lyon, 2013, v1.0, No. 11.

[6] Faust, O. Acharya, U.R. Meiburger, K.M. Molinari, F. Koh, J.E.W. Yeong, C.H. Ng, K.H. "Comparative assessment of texture features for the identification of cancer in ultrasound images: a review", Biocybernetics and Biomedical Engineering, 2018, Vol. 38, No. 2, pp. 275-296

[7] Hossain, S. Mohammadi, F. "Tumor parameter estimation considering the body geometry by thermography", Comput. Biol. Med. 2016, Vol. 76, pp. 80-93.

[8] Hossain, S. Mohammadi, F. Talebi Nejad, E. "Neural network approach for the determination of heat source parameters from surface temperature image", In: Proceedings of the Canadian conference on electrical and computer engineering (CCECE), Niagara Falls, ON. 2011. p.001109-001112.

[9] Etehadtavakol, M. and Ng, E.Y.K. "Breast thermography as a potential non-contact method in the early detection of cancer: A Review", Journal of Mechanics in Medicine and Biology, 2013, Vol. 13, No. 02, pp. 1330001

[10] Araújo, T. Aresta, G. Castro, E. Rouco, J. Aguiar, P. Eloy, C. and Campilho, A. "Classification of breast cancer histology images using Convolutional Neural Networks", PLOS ONE, 2017, Vol. 12, No. 6, pp. e0177544.

[11] Heywang-Köbrunner, S.H. Hacker, A. and Sedlacek, S. "Advantages and Disadvantages of Mammography Screening", Breast Care, 2011, Vol. 6, No. 3, pp. 2-2.

[12] Gerasimova-Chechkina, E. Toner, B. Marin, Z. Audit, B. Roux, S.G. Argoul, F. and Arneodo, A. "Comparative Multifractal Analysis of Dynamic Infrared Thermograms and X-Ray Mammograms Enlightens Changes in the Environment of Malignant Tumors", Frontiers in Physiology, 2016, Vol. 7.

[13] Garduño-Ramón, M.A. Vega-Mancilla, S.G. Morales-Henández L.A. and Osornio-Rios R.A. "Supportive Noninvasive Tool for the Diagnosis of Breast Cancer Using a Thermographic Camera as Sensor", Sensors 2017, 17, 497

[14] Amalu W.C. "A review of breast thermography", International Academy of Clinical Thermography, 2002, Assessed on 16/10/2018 pp. 1-21

[15] Ogihara, H. Hamamoto, Y. Fujita, Y. Goto, A. Nishikawa, J. and Sakaida, I. "Development of a Gastric Cancer Diagnostic Support System with a Pattern Recognition Method Using a Hyperspectral Camera", Journal of Sensors, 2016, pp. 1-6.

[16] Lehmann, T. Rossa, C. Sloboda, R. Usmani, N. and Tavakoli, M. (2016). "Needle path control during insertion in soft tissue using a force-sensorbased deflection estimator", In: Proceedings of IEEE International Conference on Advanced Intelligent Mechatronics (AIM), 2016

[17] Tosi, D. Macchi, E.G. and Cigada, A. "FibreOptic Temperature and Pressure Sensors Applied to Radiofrequency Thermal Ablation in Liver Phantom: Methodology and Experimental Measurements", Journal of Sensors, 2015, pp. 122.

[18] Han, F. Shi, G. Liang, C. Wang, L. Li, K. "A simple and efficient method for breast cancer diagnosis based on infrared thermal imaging", Cell Biochem. Biophys., 2015, Vol. 71, pp. 491-498 
[19] Cheng, L. and Tian, G.Y. "Comparison of nondestructive testing methods on detection of delaminations in composites, Journal of Sensors, 2012, pp. 1-7.

[20] Chady, T. Lopato, P. and Szymanik, B. "Terahertz and thermal testing of glass-fiber reinforced composites with impact damages", Journal of Sensors, 2012, 1-14.

[21] Chen, K. Bai, L. Chen, Y. Cheng, Y. Tian, S. and Zhu, P. "Defect automatic identification of Eddy current pulsed thermography", Journal of Sensors, 2014, pp. 1-7.

[22] Hildebrandt, C. Zeilberger, K. John Ring, E.F., and Raschner, C. "The Application of Medical Infrared Thermography in Sports Medicine", In book: An International Perspective on Topics in Sports Medicine and Sports Injury, 2012,

[23] Ring F., "Thermal Imaging Today and Its Relevance to Diabetes" J. Diabetes Sci. Technol. 2010, Vol. 4, No. 4, pp. 857-862.

[24] Sun, G. Yao, Y. Yoshinaka, R. Ikegami, M. Kim, S. "A paediatric infection screening system with a radar respiration monitor for rapid detection of seasonal influenza among outpatient children. $J$. Infect. Dis. Ther. 2014, 2:163.

[25] Tan, J.H. Ng, E.Y.K. Acharya, U.R. and Chee, C. "Automated study of ocular thermal images: Comprehensive analysis of corneal health with different age group subjects and validation", Digital Signal Processing, 2010, Vol. 20, No. 6, pp. 1579-1591.

[26] Jarrell, J. and Spanswick, C. "Diagnostic use of infrared thermography in a patient with chronic pain following electrocution: a case report", Journal of Medical Case Reports, 2009, Vol. 3, No. 1 , pp. 8992.

[27] Lahiri, B.B. Bagavathiappan, S. Jayakumar, T. and Philip, J. "Medical applications of infrared thermography: A review", Infrared Physics \& Technology, 2012, Vol. 55, No. 4, pp. 221-235.

[28] Rastgar-Jazi, M. and Mohammadi, F. "Parameters sensitivity assessment and heat source localization using infrared imaging techniques", BioMed Eng. OnLine, 2017, 16:113

[29] Gautherie M, Gros CM. "Breast thermography and cancer risk prediction". Cancer 1980, Vol. 45, pp. 51-56.

[30] González, F.J. "Thermal simulation of breast tumors". Revista Mexicana de Física, 2007, pp. 323-326.

[31] Shada, A.L. Dengel, L.T. Petroni, G.R. Smolkin, M.E. Acton, S. Slingluff, C.L. (2013) "Infrared thermography of cutaneous melanoma metastases", J. Surg. Res., Vol. 182, e9-e14.

[32] Hermans, B. Coosemans, J. and Puers, R. "Integration of Sensors and Electronics in Textile for use in Infant Medicine", In Proceedings of the European Microlectronics and Packaging Conference and Exhibition, June 12-15, 2005, pp. 588-592.

[33] Catrysse, M. "Towards the Integration of Textile Sensors in a Wireless Monitoring Suit", Sensors and Actuators, 2004, Vol. A114, pp. 302311.

[34] Keyserlignk, J. and Ahlgren, P. "Infrared imaging of the breast: initial reappraisal using high resolution digital technology in 100 Successive Cases of Stage 1 and 2 breast cancer", Breast J., 1998, Vol. 4, pp. 245-251

[35] Parisky, Y.R, Sardi A. Hamm, R. "Efficacy of computerized infrared imaging analysis to evaluate mammographically suspicious lesions", AJR Am. J. Roentgenol. 2003; Vol. 180, pp. 263269

[36] Gore, J.P. and Xu, L.X. "Thermal Imaging for Biological and Medical Diagnostics", In book: Biomedical Photonics Handbook, CRC Press, 2003 Ch. 17, pp. 17.

[37] De Oliveira, J. Conci, A. Pérez, M.G. Andaluz, V.H. "Segmentation of infrared images: A new technology for early detection of breast diseases", In: Proceedings of the IEEE International Conference on Industrial Technology (ICIT), Seville, Spain, 2015, pp. 1765-1771.

[38] Acharya, U.R. Ng, E. Tan, J.H. Sree, S.V. "Thermography based breast cancer detection using texture features and support vector machine", J. Med. Syst., 2012, Vol. 36, pp. 15031510.

[39] Prabha, S. Sujatha, C. Ramakrishnan, S. "Asymmetry analysis of breast thermograms using BM3D technique and statistical texture features", In: Proceedings of the 3rd International Conference on Informatics, Electronics \& Vision (ICIEV), Dhaka, Bangladesh, 23-24 May 2014; pp. 1-4.

[40] Bjurstam, N. Hedberg, K. Hultborn, K. Johansson, N. Johnsen, C. "Diagnosis of breast carcinoma", In: Progress in Surgery, Karger Publishers, London, UK, 1974; pp. 1-65.

[41] Lohbeck, H.U. "Thermography Instead of Mammography?" In: Cancer Management in Man, Springer, New York, NY, USA, 1989; pp. 96-102. 